\title{
Technical note: Measurement of chemically resolved volume equivalent diameter and effective density of particles by AAC-SPAMS
}

\author{
Long Peng ${ }^{1,2}$, Lei $\mathrm{Li}^{4}$, Guohua Zhang ${ }^{1,3}$, Xubing Du ${ }^{4}$, Xinming Wang ${ }^{1,3}$, Ping'an Peng ${ }^{1,3}$, Guoying Sheng ${ }^{1}$, and \\ Xinhui $\mathbf{B i}^{1,3}$ \\ ${ }^{1}$ State Key Laboratory of Organic Geochemistry and Guangdong Provincial Key Laboratory of Environmental Protection and \\ Resources Utilization, Guangzhou Institute of Geochemistry, Chinese Academy of Sciences, Guangzhou 510640, China \\ ${ }^{2}$ University of Chinese Academy of Sciences, Beijing 100049, China \\ ${ }^{3}$ Guangdong-Hong Kong-Macao Joint Laboratory for Environmental Pollution and Control, Guangzhou 510640, China \\ ${ }^{4}$ Institute of Mass Spectrometer and Atmospheric Environment, Jinan University, Guangzhou 510632, China
}

Correspondence: Xinhui Bi (bixh@gig.ac.cn) and Guohua Zhang (zhanggh@gig.ac.cn)

Received: 7 October 2020 - Discussion started: 26 October 2020

Revised: 26 February 2021 - Accepted: 2 March 2021 - Published: 12 April 2021

\begin{abstract}
Size and effective density $\left(\rho_{\mathrm{e}}\right)$ are important properties of aerosol particles and are related to their influences on human health and the global climate. The volume equivalent diameter $\left(D_{\mathrm{ve}}\right)$ is an intrinsic property that is used to evaluate particle size. Three definitions of $\rho_{\mathrm{e}}$ are generally used to characterize the physical property of a particle as an alternative to particle density, in which only the $\rho_{\mathrm{e}}^{\mathrm{II}}$, defined as the ratio of particle density $\left(\rho_{\mathrm{p}}\right)$ to a dynamic shape factor $(\chi)$, has the characteristic of being independent of particle size. However, it is still challenging to simultaneously characterize the $D_{\mathrm{ve}}$ and $\rho_{\mathrm{e}}^{\mathrm{II}}$ of aspherical particles. Here, we present a novel system that classifies particles with their aerodynamic diameter $\left(D_{\mathrm{a}}\right)$ by aerodynamic aerosol classifier (AAC) and determines their vacuum aerodynamic diameter $\left(D_{\text {va }}\right)$ by single-particle aerosol mass spectrometry (SPAMS) to achieve a measurement of $D_{\mathrm{ve}}$ and $\rho_{\mathrm{e}}^{\mathrm{II}}$. The reliability of the AAC-SPAMS system for accurately obtaining $D_{\text {ve }}$ and $\rho_{\mathrm{e}}^{\mathrm{II}}$ is verified based on the result that the deviation between the measured and theoretical values is less than $6 \%$ for the size-resolved spherical polystyrene latex (PSL). The AACSPAMS system was applied to characterize the $D_{\text {ve }}$ and $\rho_{\mathrm{e}}^{\text {II }}$ of $\left(\mathrm{NH}_{4}\right)_{2} \mathrm{SO}_{4}$ and $\mathrm{NaNO}_{3}$ particles, suggesting that these particles are aspherical and their $\rho_{\mathrm{e}}^{\mathrm{II}}$ is independent of particle size. Finally, the AAC-SPAMS system was deployed in a field measurement, showing that it is a powerful technique to characterize the chemically resolved $D_{\mathrm{ve}}$ and $\rho_{\mathrm{e}}^{\mathrm{II}}$ of particles in real time.
\end{abstract}

\section{Introduction}

Size and particle density $\left(\rho_{\mathrm{p}}\right)$ are critical parameters of aerosol particles in quantifying the impact of aerosols on air quality, human health and global climate change (Buseck and Posfai, 1999; Pöschl, 2005; Pitz et al., 2003). Effective density $\left(\rho_{\mathrm{e}}\right)$ has been adopted to characterize the physical property of a particle as an alternative to $\rho_{\mathrm{p}}$, since $\rho_{\mathrm{p}}$ for aspherical aerosol particles is hardly measured (Sumlin et al., 2018; Katrib et al., 2005). Size and $\rho_{\mathrm{e}}$ govern the transport properties of a particle both in the atmosphere and in the human respiratory system (Seinfeld and Pandis, 1998; Liu and Daum, 2008) and directly and/or indirectly influence the potential of the particle to absorb or reflect solar radiation (Tang, 1997; Zhao et al., 2019; Liu and Daum, 2008). $\rho_{\mathrm{e}}$ can also provide information concerning particle morphology (Yon et al., 2015) and serve as a tracer for atmospheric processing (Guo et al., 2014; Yin et al., 2015; Liu et al., 2015). However, the quantitative relationship between aerosol properties, namely size and $\rho_{\mathrm{e}}$, and their effects on air quality, human health, and global climate change are not yet well understood, which is partly because important aerosol properties cannot be measured by current techniques. 


\subsection{Size}

Size is a fundamental property of particles and can be parameterized by the physical quantity of volume equivalent diameter $\left(D_{\mathrm{ve}}\right)$. Defined as the diameter of a spherical particle with the same volume as the particle (DeCarlo et al., 2004), $D_{\text {ve }}$ is an intrinsic physical quantity that can be used to evaluate the actual size of the particle. However, to date, atmospheric science usually describes particle size by other diameter definitions, such as the electric mobility diameter $\left(D_{\mathrm{m}}\right)$, aerodynamic equivalent diameter $\left(D_{\mathrm{a}}\right)$, and vacuum aerodynamic equivalent diameter $\left(D_{\mathrm{va}}\right)$, whose relationships with $D_{\text {ve }}$ are shown in Eqs. (1)-(3), respectively:

$$
\begin{aligned}
& \frac{D_{\mathrm{m}}}{C_{\mathrm{c}}\left(D_{\mathrm{m}}\right)}=\frac{D_{\mathrm{ve}}}{C_{\mathrm{c}}\left(D_{\mathrm{ve}}\right)} \chi_{\mathrm{t}}, \\
& D_{\mathrm{a}}=D_{\mathrm{ve}} \sqrt{\frac{\rho_{\mathrm{p}} C_{\mathrm{c}}\left(D_{\mathrm{ve}}\right)}{\chi_{\mathrm{t}} \cdot \rho_{0} \cdot C_{\mathrm{c}}\left(D_{\mathrm{a}}\right)}}, \\
& D_{\mathrm{va}}=\frac{\rho_{\mathrm{p}}}{\rho_{0}} \frac{D_{\mathrm{ve}}}{\chi_{\mathrm{v}}},
\end{aligned}
$$

where $C_{\mathrm{c}}(D)$ is the Cunningham slip correction factor, $\chi_{\mathrm{t}}$ and $\chi_{\mathrm{v}}$ represent the aerosol dynamic shape factor $(\chi)$ in the transition regime and in the free-molecule regime, respectively, and $\rho_{0}$ represents the unit density of $1.0 \mathrm{~g} / \mathrm{cm}^{3}$. From these definitions, it can be seen that $D_{\mathrm{m}}, D_{\mathrm{a}}$, and $D_{\text {va }}$ are originally derived from $D_{\mathrm{ve}}$, but in actuality they do not reflect the actual size of the aspherical particle. Meanwhile, $D_{\text {ve }}$ of aspherical particles cannot be easily obtained, which limits its application in the scientific community.

\subsection{Effective density}

At present, three definitions of $\rho_{\mathrm{e}}$ are introduced in atmospheric science (DeCarlo et al., 2004): the first definition $\left(\rho_{\mathrm{e}}^{\mathrm{I}}\right)$ is the ratio of the measured particle mass $\left(m_{\mathrm{p}}\right)$ to the particle volume $(V)$ calculated assuming a spherical particle with a diameter equal to the measured $D_{\mathrm{m}}$, the second definition $\left(\rho_{\mathrm{e}}^{\mathrm{II}}\right)$ is the ratio of $\rho_{\mathrm{p}}$ to $\chi$ (Hand and Kreidenweis, 2002), and the third definition $\left(\rho_{\mathrm{e}}^{\mathrm{III}}\right)$ is the ratio of $D_{\mathrm{m}}$ and $D_{\text {va }}$, expressed in Eqs. (4)-(6), respectively.

$\rho_{\mathrm{e}}^{\mathrm{I}}=\frac{6 m_{\mathrm{p}}}{\pi D_{\mathrm{m}}^{3}}$,

$\rho_{\mathrm{e}}^{\mathrm{II}}=\frac{\rho_{\mathrm{p}}}{\chi}$,

$\rho_{\mathrm{e}}^{\mathrm{III}}=\frac{D_{\mathrm{va}}}{D_{\mathrm{m}}} \rho_{0}$.

The definitions of $\rho_{\mathrm{e}}^{\mathrm{I}}$ and $\rho_{\mathrm{e}}^{\mathrm{III}}$ can be derived into their final forms, as shown in the Eqs. (7) and (8), respectively.

$$
\begin{aligned}
& \rho_{\mathrm{e}}^{\mathrm{I}}=\frac{\rho}{\chi_{\mathrm{t}}^{3}} \cdot\left(\frac{C_{\mathrm{c}}\left(D_{\mathrm{ve}}\right)}{C_{\mathrm{c}}\left(D_{\mathrm{m}}\right)}\right)^{3} \\
& \rho_{\mathrm{e}}^{\mathrm{III}}=\rho \cdot \frac{C_{\mathrm{c}}\left(D_{\mathrm{ve}}\right)}{\chi^{2} \cdot C_{\mathrm{c}}\left(D_{\mathrm{m}}\right)}
\end{aligned}
$$

Equation (7) is derived from combining Eq. (1) with Eq. (4), in which $m_{\mathrm{p}}$ is equal to $1 / 6 \rho \cdot D_{\mathrm{ve}}^{3}$. The detailed derivation of Eq. (8) is presented in Schneider et al. (2006). A variety of methods are developed to characterize $\rho_{\mathrm{e}}^{\mathrm{I}}$ and $\rho_{\mathrm{e}}^{\mathrm{III}}$, among which the more advanced methods are to achieve the measurement of the chemically resolved effective density. Combining a single-particle soot photometer (SP2) with a (volatility) tandem differential mobility analyzer ((VT)DMA) can measure the $\rho_{\mathrm{e}}^{\mathrm{I}}$ of particles mixed with soot (Y. Zhang et al., 2016; Wu et al., 2019; Han et al., 2019). The measurement of chemically resolved $\rho_{\mathrm{e}}^{\mathrm{III}}$ can be achieved by coupling a DMA with an online aerosol mass spectrometer such as the Single-Particle Laser Ablation Time-of-Flight Mass Spectrometer (SPLAT) (Zelenyuk et al., 2005, 2006; Alexander et al., 2016), aerosol mass spectrometer (AMS) (Dinar et al., 2006; Schneider et al., 2006; Kiselev et al., 2010), aerosol time-of-flight mass spectrometer (ATOFMS) (Spencer and Prather, 2006; Spencer et al., 2007), and single-particle aerosol mass spectrometry (SPAMS) (G. Zhang et al., 2016; Zhai et al., 2017). However, the $\rho_{\mathrm{e}}^{\mathrm{I}}$ and $\rho_{\mathrm{e}}^{\mathrm{III}}$ are demonstrated to have the inherent characteristic of decreasing with increasing particle size, which will be presented in a separate publication. Therefore, it will introduce systemic error when assessing the particle's impact on visibility, human health, and climate change from the physical quantities in $\rho_{\mathrm{e}}^{\mathrm{I}}$ and $\rho_{\mathrm{e}}^{\mathrm{III}}$. In contrast, $\rho_{\mathrm{e}}^{\mathrm{II}}$ is independent of particle size. For example, for soot particles with $\chi$ of 2.5 and $\rho_{\mathrm{p}}$ of $1.80 \mathrm{~g} / \mathrm{cm}^{3}$, the calculated $\rho_{\mathrm{e}}^{\mathrm{I}}, \rho_{\mathrm{e}}^{\mathrm{II}}$, and $\rho_{\mathrm{e}}^{\mathrm{III}}$ are $0.43,0.72$, and $0.45 \mathrm{~g} / \mathrm{cm}^{3}$ at $D_{\mathrm{m}}$ of $40 \mathrm{~nm}$ and $0.22,0.72$, and $0.36 \mathrm{~g} / \mathrm{cm}^{3}$ at $D_{\mathrm{m}}$ of $550 \mathrm{~nm}$, respectively. The big gap between the three definitions of effective density suggests that they should be carefully treated when characterizing the particles. However, the $\rho_{\mathrm{e}}^{\mathrm{II}}$ has not been widely applied in atmospheric sciences because of the lack of measurement techniques. Previous literature has tried to retrieve the $\rho_{\mathrm{e}}^{\mathrm{II}}$ and the real part in the refractive index (n) through a fitting procedure that compares the measured light-scattering intensity of particles $\left(R_{\text {meas }}\right)$ to the theoretical values $\left(R_{\text {theory,test }}\right)$ calculated by a series of $n$ and $\rho_{\mathrm{e}}^{\mathrm{II}}$ values (Moffet and Prather, 2005; Moffet et al., 2008; G. Zhang et al., 2016). Moffet and Prather (2005) successfully obtained $\rho_{\mathrm{e}}^{\mathrm{II}}$ for spherical particles via single-particle mass spectrometry. However, subject to the accuracy of Mie theory for the aspherical particles, dry $\mathrm{NaCl}$ and calcium-rich dust particles failed to fit the $R_{\text {theory,test }}$ well to $R_{\text {meas }}$ (Moffet et al., 2008). Similarly, G. Zhang et al. (2016) failed to simultaneously retrieve $\rho_{\mathrm{e}}^{\text {II }}$ and $n$ for $\left(\mathrm{NH}_{4}\right)_{2} \mathrm{SO}_{4}$ and $\mathrm{NaNO}_{3}$ particles. To the best of our knowledge, there is no appropriate technique to achieve the measurement of $\rho_{\mathrm{e}}^{\mathrm{II}}$ for aspherical particles.

The aim of the present work is to develop a method to simultaneously obtain $D_{\text {ve }}$ and $\rho_{\mathrm{e}}^{\mathrm{II}}$ for aspherical particles. For simplicity, the symbol $\rho_{\mathrm{e}}$ in the following text refers to the definition of $\rho_{\mathrm{e}}^{\mathrm{II}}$. The established system of aerodynamic aerosol classifier single-particle aerosol mass spectrometry (AAC-SPAMS) is capable of characterizing the $D_{\mathrm{a}}$ and $D_{\text {va }}$ 


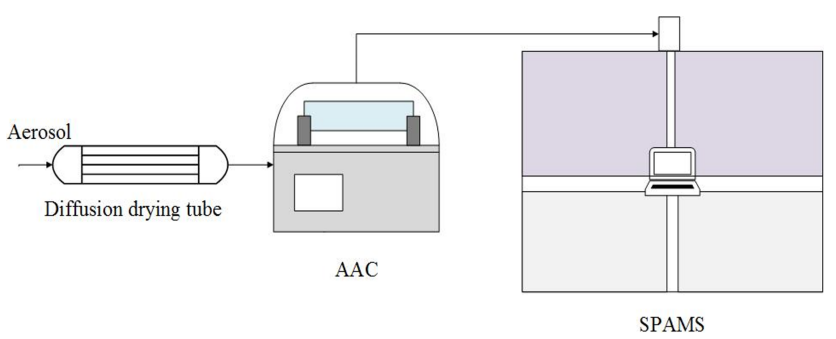

Figure 1. Schematic diagram of the AAC-SPAMS system $(0.3 \mathrm{~L} / \mathrm{min})$. The diffusion drying tube is filled with orange silica gel, which reduces the RH to $5 \%-15 \%$.

of particles, which can be applied to theoretically derive $D_{\mathrm{ve}}$ and $\rho_{\mathrm{e}}$. To verify the reliability of the AAC-SPAMS system, we apply it to measure the $D_{\mathrm{ve}}$ and $\rho_{\mathrm{e}}$ of the spherical particles of polystyrene latex (PSL). The results are in good agreement with the theoretical values. Finally, the AAC-SPAMS system is applied to measure the $D_{\text {ve }}$ and $\rho_{\mathrm{e}}$ for $\left(\mathrm{NH}_{4}\right)_{2} \mathrm{SO}_{4}$ and $\mathrm{NaNO}_{3}$ particles and for the chemically resolved atmospheric particles.

\section{Experimental section}

\subsection{Measurement system}

Figure 1 shows a schematic diagram of the AAC-SPAMS system. The particles are first dried by a diffusion drying tube (TSI 9302, USA), classified by AAC (Cambustion Ltd., UK) based on the $D_{\mathrm{a}}$, and then transported into SPAMS, where the $D_{\mathrm{va}}$ and the mass spectra of individual particles are obtained. The working principle of the AAC is described in detail elsewhere (Tavakoli and Olfert, 2013). AAC consists of two coaxial cylinders that rotate at the same rotational speed. Polydisperse particles enter into the space between the cylinders (i.e., the classification column) and experience a centrifugal force that causes them to move toward the outer cylinder. The particles to be classified can leave the classification column with the particle-free sheath flow and finally exit the AAC with the sample flow. Thus, the $D_{\text {a values }}$ of classified particles can be derived from their relationship with their relaxation time $(\tau)$, as shown in Eq. (9):

$\tau=\frac{C_{\mathrm{c}}\left(D_{\mathrm{a}}\right) \cdot \rho_{0} \cdot D_{\mathrm{a}}^{2}}{18 \mu}$,

where $\mu$ is the gas dynamic viscosity. Particles with large relaxation times impact and adhere to the outer cylinder, while particles with small relaxation times exit the classifier with the exhaust flow. In this study, the exhaust flow from the AAC was about $0.3 \mathrm{~L} / \mathrm{min}$, and the size resolution parameter of the AAC was set as 40 .

Detailed information about the operation of SPAMS (Hexin Analytical Instrument Co., Ltd., China) is given elsewhere (Li et al., 2011). Briefly, the particles are introduced into the vacuum system through a $0.1 \mathrm{~mm}$ critical orifice and are gradually collimated into a beam in the aerodynamic lens. Two continuous diode Nd:YAG laser beams $(532 \mathrm{~nm})$ are used to aerodynamically size the particles, which are subsequently desorbed and ionized by a pulsed laser $(266 \mathrm{~nm})$ that is triggered based on the velocity of a specific particle. The generated positive and negative ions are recorded with the corresponding particle size. The $D_{\mathrm{va}}$ of the particle is related to the transit time between the two laser beams $(532 \mathrm{~nm})$ in SPAMS, which can be obtained by using a calibration curve generated from the measured transit times of a PSL series with predefined sizes (nominal diameters).

\subsection{Laboratory experiments}

Dried spherical PSL (Nanosphere Size Standards, Duke Scientific Corp., Palo Alto) $\left(\rho_{\mathrm{p}}=1.055 \mathrm{~g} / \mathrm{cm}^{3}\right.$ and $\left.\chi=1.0\right)$ with $D_{\text {ve }}$ values of $203 \pm 5,310 \pm 6,510 \pm 5$, and $740 \pm 6 \mathrm{~nm}$ were used in the AAC-SPAMS system, and the $D_{\text {ve }}$ was verified by Scanning Mobility Particle Sizer (Model 3938, TSI Inc., USA). The PSL particles were first classified by AAC, and then their $D_{\mathrm{va}}$ values were obtained by SPAMS. ACC-SPAMS was also applied to the particles of $\left(\mathrm{NH}_{4}\right)_{2} \mathrm{SO}_{4}$ $\left(\rho_{\mathrm{p}}=1.77 \mathrm{~g} / \mathrm{cm}^{3}\right)$ and $\mathrm{NaNO}_{3}\left(\rho_{\mathrm{p}}=2.26 \mathrm{~g} / \mathrm{cm}^{3}\right)$ with $D_{\mathrm{a}}$ values of $250.0,350.0,450.0$, and $550.0 \mathrm{~nm}$. Besides, to obtain the measurement uncertainty of the AAC, the $D_{\text {a }}$ values of these PSL particles were measured to be $212.8 \pm 0.2$, $324.7 \pm 0.4,529.9 \pm 0.4$, and $767.5 \pm 0.4$ by the system of AAC condensation particle counter (CPC), respectively. It shows that the AAC has the deviations of $1.1 \%, 1.3 \%, 0.8 \%$, and $0.7 \%$ for determining the $D_{\mathrm{a}}$ values of the particles.

\subsection{Ambient sampling}

For field observations, the AAC-SPAMS system was deployed in Science and Technology Enterprise Accelerator A2 Block, Guangzhou, China, to characterize the $D_{\mathrm{ve}}, \rho_{\mathrm{e}}$, and chemical compositions of aerosol particles. The sampling inlet was hung $2.5 \mathrm{~m}$ from the third floor $(\sim 12 \mathrm{~m}$ above ground level). Ambient aerosol particles were introduced into the AAC through a $5 \mathrm{~m}$ long conductive silicone tube with an inner diameter of $6 \mathrm{~mm}$ and a $\mathrm{PM}_{2.5}$ cyclone inlet. The sampling flow from the $\mathrm{PM}_{2.5}$ cyclone inlet was $3 \mathrm{~L} / \mathrm{min}$, and the residence time in the conductive silicone tube was approximately $5 \mathrm{~s}$. Particles with the $D_{\mathrm{a}}$ of $250.0,350.0,450.0$, and $550.0 \mathrm{~nm}$ were classified by the AAC. The sampling time for the particles of each $D_{\mathrm{a}}$ was approximately $10 \mathrm{~min}$. From 68 July 2019, approximately 129869 ionized particles were obtained from nine rounds of measurement. The sampling details are shown in Table S1 in the Supplement. The number of ionized particles with the $D_{\text {a }}$ of 250.0, 350.0, 450.0, and $550.0 \mathrm{~nm}$ is $35609,38374,31910$, and 23976 , respectively. The sampled $\sim 100000$ particles are first classified by using an adaptive resonance theory neural network (ART-2a) 
(Song et al., 1999) with a vigilance factor of 0.75 , a learning rate of 0.05 , and 20 iterations.

\subsection{Theoretical derivation of $D_{\mathrm{ve}}$ and $\rho_{\mathrm{e}}$ from $D_{\mathrm{a}}$ and $D_{\text {va }}$}

In this study, the calculations of $D_{\mathrm{ve}}$ and $\rho_{\mathrm{e}}$ for unknown particles are theoretically derived from $D_{\text {a }}$ and $D_{\text {va }}$. Combining Eqs. (2) and (3), we obtain Eq. (10):

$C_{\mathrm{c}}\left(D_{\mathrm{a}}\right) \frac{D_{\mathrm{a}}^{2}}{D_{\mathrm{va}}}=D_{\mathrm{ve}} C_{\mathrm{c}}\left(D_{\mathrm{ve}}\right) \frac{\chi_{\mathrm{v}}}{\chi_{\mathrm{t}}}$.

Based on the approximation between $\chi_{\mathrm{v}}$ and $\chi_{\mathrm{t}}\left(\chi_{\mathrm{v}} \approx \chi_{\mathrm{t}}=\right.$ $\left.\chi_{\mathrm{a}}\right)$ (DeCarlo et al., 2004), Eq. (10) becomes Eq. (11):

$C_{\mathrm{c}}\left(D_{\mathrm{a}}\right) \frac{D_{\mathrm{a}}^{2}}{D_{\mathrm{va}}}=D_{\mathrm{ve}} C_{\mathrm{c}}\left(D_{\mathrm{ve}}\right)$.

The Cunningham slip correction factor is calculated by Eq. (12) (Peng and Bi, 2020):

$C_{\mathrm{c}}(D)=1+\frac{\lambda}{D}\left(A+B \cdot \exp \left(\frac{C \cdot D}{\lambda}\right)\right)$,

where $\lambda$ is the mean free path of the gas molecules and $A, B$, and $C$ are empirically determined constants specific to the analysis system. The values of $A, B$, and $C$ are 2.33, 0.966, and -0.498 provided by the manual of the AAC, respectively. Substituting Eq. (12) into Eq. (11) obtains Eq. (13).

$$
\begin{aligned}
\frac{D_{\mathrm{a}}^{2}}{D_{\mathrm{va}}} & +\frac{D_{\mathrm{a}} \cdot \lambda}{D_{\mathrm{va}}}\left(A+B \cdot \exp \left(\frac{C \cdot D_{\mathrm{a}}}{\lambda}\right)\right) \\
& =D_{\mathrm{ve}}+\lambda\left(A+B \cdot \exp \left(\frac{C \cdot D_{\mathrm{ve}}}{\lambda}\right)\right)
\end{aligned}
$$

If the $D_{\mathrm{a}}$ and $D_{\mathrm{va}}$ of an unknown particle can be measured, its $D_{\mathrm{ve}}$ could be calculated according to Eq. (13). Finally, the $\rho_{\mathrm{e}}$ value of the particles is calculated by the $D_{\mathrm{va}}$ and $D_{\mathrm{ve}}$ values according to Eq. (14), which is obtained by combining Eqs. (3) and (5):

$\rho_{\mathrm{e}}=\frac{\rho_{\mathrm{p}}}{\chi_{\mathrm{a}}}=\frac{D_{\mathrm{va}}}{\rho_{0} \cdot D_{\mathrm{ve}}}$.

Thus, we can obtain both the $D_{\mathrm{ve}}$ and $\rho_{\mathrm{e}}$ values of unknown particles based on the $D_{\mathrm{a}}$ and $D_{\mathrm{va}}$ values. Because the AAC and SPAMS instruments have the ability to determine $D_{\mathrm{a}}$ and $D_{\text {va }}$, the AAC-SPAMS system developed in this study can be used to obtain the $D_{\mathrm{ve}}$ and $\rho_{\mathrm{e}}$ values for unknown particles.

\section{Results and discussion}

\subsection{Verification of the AAC-SPAMS system to obtain $D_{\text {ve }}$ and $\rho_{\mathrm{e}}$}

The $D_{\mathrm{va}}$ distribution of PSL particles with predefined $D_{\mathrm{ve}}$ values after being screened by the AAC is shown in Fig. S1 in the Supplement. Gaussian fitting is used to obtain the peak $D_{\text {va }}$ for each size PSL with $R^{2}$ fitting coefficient over 0.98 . Each fitting has a full width at half maximum (FWHM) of $6.6 \%, 4.4 \%, 2.3 \%$, and $2.2 \%$, and the corresponding peaks are $215.8,319.0,532.1$, and $803.5 \mathrm{~nm}$, respectively. Substituting the $D_{\mathrm{a}}$ and $D_{\mathrm{va}}$ values of PSL into Eq. (11), the measured $D_{\mathrm{ve}}\left(D_{\mathrm{ve}, \mathrm{me}}\right)$ of PSL from the AAC-SPAMS system is $203.6,309.7,511.6$, and $737.2 \mathrm{~nm}$, respectively (Fig. 2a). Thus, the deviations between the theoretical $D_{\mathrm{ve}}\left(D_{\mathrm{ve}, \mathrm{th}}\right)$ and

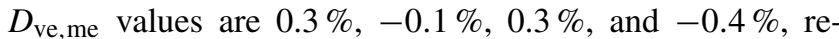
spectively. On the other hand, the measured $\rho_{\mathrm{e}}\left(\rho_{\mathrm{e}, \mathrm{me}}\right)$ values of the particles, calculated from the $D_{\mathrm{va}}$ and $D_{\mathrm{ve}, \mathrm{me}}$ values with Eq. (14), are $1.1,1.0,1.0$, and $1.1 \mathrm{~g} / \mathrm{cm}^{3}$, respectively (Fig. 2b). Comparing to the theoretical $\rho_{\mathrm{e}}\left(\rho_{\mathrm{e}}\right.$,th $)$ (i.e., $1.055 \mathrm{~g} / \mathrm{cm}^{3}$ of PSL particles), the deviations of $\rho_{\mathrm{e}, \text { me }}$ are determined to be $4.3 \%,-5.2 \%,-5.2 \%$, and $4.3 \%$, respectively. That is, the deviations of $D_{\mathrm{ve}, \mathrm{me}}$ and $\rho_{\mathrm{e}, \mathrm{me}}$ obtained by the AAC-SPAMS system are within $1 \%$ and $6 \%$, respectively.

\subsection{Application of the AAC-SPAMS system for obtaining $D_{\text {ve }}$ and $\rho_{\mathrm{e}}$ of $\left(\mathrm{NH}_{4}\right)_{2} \mathrm{SO}_{4}$ and $\mathrm{NaNO}_{3}$}

Figure $\mathrm{S} 2$ shows the $D_{\text {va }}$ distributions of $\left(\mathrm{NH}_{4}\right)_{2} \mathrm{SO}_{4}$ and $\mathrm{NaNO}_{3}$ particles with $D_{\mathrm{a}}$ values of $250.0,350.0,450.0$, and $550.0 \mathrm{~nm}$ screened by the AAC. The $D_{\text {va }}$ peaks are obtained by Gaussian fitting, with $R^{2}$ values over 0.93 and FWHM values ranging from $7.6 \%$ to $10.6 \%$. The $\left(\mathrm{NH}_{4}\right)_{2} \mathrm{SO}_{4}$ particles have $D_{\text {va }}$ values of $300.0,418.0,551.1$, and $695.1 \mathrm{~nm}$ (Fig. S2), which correspond to particles possessing $D_{\mathrm{ve}, \mathrm{me}}$ values of $177.3,254.4,331.8$, and $409.3 \mathrm{~nm}$, respectively, according to Eq. (11). Substituting the values of $D_{\mathrm{va}}$ and $D_{\mathrm{ve}}$,me into Eq. (12), the $\rho_{\mathrm{e}, \mathrm{me}}$ values are $1.7,1.6,1.6$, and $1.7 \mathrm{~g} / \mathrm{cm}^{3}$ (Fig. 3a), respectively. Similarly, the selected $\mathrm{NaNO}_{3}$ particles are determined to have $D_{\text {va }}$ values of 321.0, 454.9, 599.8 , and $755.3 \mathrm{~nm}$ (Fig. S2), corresponding to $D_{\mathrm{ve}, \mathrm{me}} \mathrm{val}-$ ues of 150.1, 218.2, 287.0, and $355.9 \mathrm{~nm}$, respectively. The $\rho_{\mathrm{e}}$,me values of the $\mathrm{NaNO}_{3}$ particles are 2.2, 2.0, 2.0, and $2.1 \mathrm{~g} / \mathrm{cm}^{3}$ (Fig. 3b), respectively. Figure 3 also shows that the $\rho_{\mathrm{e}}$,me values of the $\mathrm{NaNO}_{3}$ and $\left(\mathrm{NH}_{4}\right)_{2} \mathrm{SO}_{4}$ particles with different $D_{\text {a }}$ deviate from their average values with the maximum of $5.9 \%$ and $4.8 \%$, respectively, which are identical with the deviation for the $\rho_{\mathrm{e}, \mathrm{me}}$ of PSL particles. These deviations may be derived from the calibration of particle $D_{\mathrm{va}}$ from the SPAMS. While the $R^{2}$ of size calibration curve is 0.999 , the curve of exponential function is found to slightly deviate from the data points measured by SPAMS. For example, the size calibration function produces the deviation of $-4.4 \%$ and $3.1 \%$ from the data points of 310 and $740 \mathrm{~nm}$, respectively.

Taking the systematic error into account, the slight difference of the $\rho_{\mathrm{e}, \mathrm{me}}$ values for the four sizes suggests that the $\rho_{\mathrm{e}}$ of $\left(\mathrm{NH}_{4}\right)_{2} \mathrm{SO}_{4}$ and $\mathrm{NaNO}_{3}$ particles is independent of particle size from 250.0 to $550.0 \mathrm{~nm}$. It is determined by the definition of effective density used in this study, which 

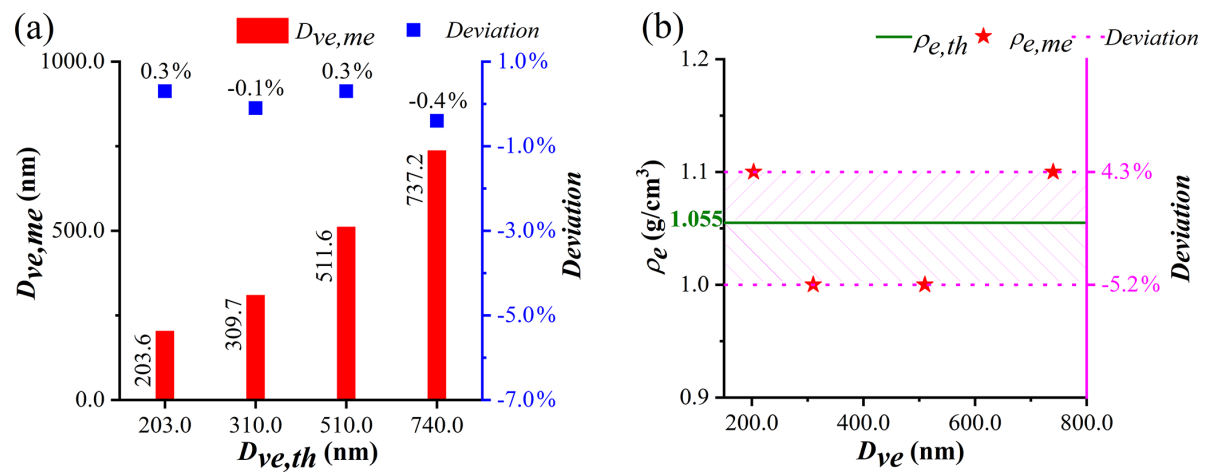

Figure 2. (a) Comparison between the measured $D_{\mathrm{ve}}\left(D_{\mathrm{ve}, \mathrm{me}}\right)$ and the theoretical $D_{\mathrm{ve}}\left(D_{\mathrm{ve}, \text { th }}\right)$ of the PSL particles. (b) Comparison between the measured $\rho_{\mathrm{e}}\left(\rho_{\mathrm{e}, \mathrm{me}}\right)$ and the theoretical $\rho_{\mathrm{e}}\left(\rho_{\mathrm{e}}, \mathrm{th}\right)$ of the PSL particles.
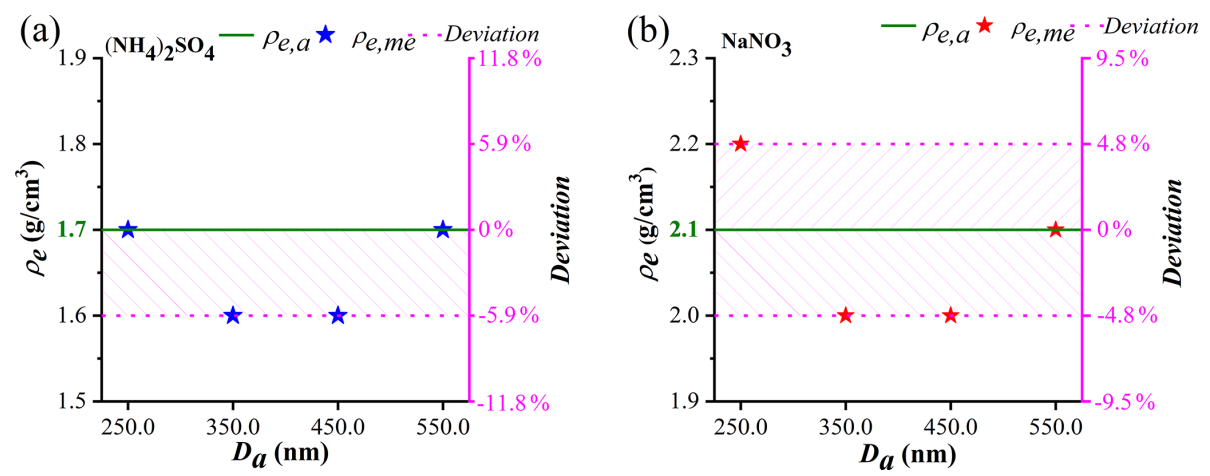

Figure 3. (a) Comparison between the measured $\rho_{\mathrm{e}}\left(\rho_{\mathrm{e}, \mathrm{me}}\right)$ and average $\rho_{\mathrm{e}}\left(\rho_{\mathrm{e}, \mathrm{a}}\right)$ values of the $\left(\mathrm{NH}_{4}\right)_{2} \mathrm{SO}_{4}$ particles. (b) Comparison between the measured $\rho_{\mathrm{e}}\left(\rho_{\mathrm{e}, \mathrm{me}}\right)$ and average $\rho_{\mathrm{e}}\left(\rho_{\mathrm{e}, \mathrm{a}}\right)$ values of the $\mathrm{NaNO}_{3}$ particles.

keeps constant as long as the $\chi_{\mathrm{a}}$ of the particles does not change with particle size for pure compound. The average $\rho_{\mathrm{e}, \text { me }}$ values of $\left(\mathrm{NH}_{4}\right)_{2} \mathrm{SO}_{4}$ and $\mathrm{NaNO}_{3}$ particles are calculated to be $1.7 \pm 0.1$ and $2.1 \pm 0.1 \mathrm{~g} / \mathrm{cm}^{3}$, which are lower than the $\rho_{\mathrm{p}}$ of $\left(\mathrm{NH}_{4}\right)_{2} \mathrm{SO}_{4}\left(1.77 \mathrm{~g} / \mathrm{cm}^{3}\right)$ and $\mathrm{NaNO}_{3}$ $\left(2.27 \mathrm{~g} / \mathrm{cm}^{3}\right)$. This is partly caused by the $\chi_{\mathrm{a}}$, which can be used to parameterize the morphology. According to Eq. (14), the $\chi_{\mathrm{a}}$ with different $D_{\mathrm{a}}$ are calculated to be $1.04,1.11,1.11$, and 1.04 for $\left(\mathrm{NH}_{4}\right)_{2} \mathrm{SO}_{4}$ particles and 1.03, 1.14, 1.14, and 1.08 for $\mathrm{NaNO}_{3}$ particles. Thus, the average $\chi_{\mathrm{a}}$ values of the $\left(\mathrm{NH}_{4}\right)_{2} \mathrm{SO}_{4}$ and $\mathrm{NaNO}_{3}$ particles are determined to be $1.07 \pm 0.04$ and $1.10 \pm 0.05$, respectively, indicating that these particles are aspherical.

The asphericity of $\left(\mathrm{NH}_{4}\right)_{2} \mathrm{SO}_{4}$ determined by AACSPAMS system is consistent with the previous studies reporting that the $\chi_{\mathrm{a}}$ of $\left(\mathrm{NH}_{4}\right)_{2} \mathrm{SO}_{4}$ were larger than the value of 1.03 (Zelenyuk et al., 2006; Beranek et al., 2012; G. Zhang et al., 2016). However, previous studies found that the $\mathrm{NaNO}_{3}$ particles had different morphology. G. Zhang et al. (2016) observed that $\mathrm{NaNO}_{3}$ had the $\chi_{\mathrm{a}}$ of 1.09-1.13, while Hoffman et al. (2004) found that $\mathrm{NaNO}_{3}$ particle had a round droplet-like shape even at $15 \% \mathrm{RH}$, supported by the consistency between the measured value of "anhydrous" droplet density and the calculated value of "anhydrous" so- lution droplet (Zelenyuk et al., 2005). Eclectically, Tang and Munkelwitz (1994) studied that most of the $\mathrm{NaNO}_{3}$ particles crystallized between $20 \%$ and $30 \%$ RH but some persisted down to $10 \%$ RH to keep solution droplets. Notably, the spherical $\mathrm{NaNO}_{3}$ particles at low RH observed by Hoffman et al. (2004) were dried in the sticky carbon tape, which might affect the phase transition of droplet-like $\mathrm{NaNO}_{3}$ particles. In this study, most $\mathrm{NaNO}_{3}$ particles might crystallize because the $\mathrm{RH}$ of the aerosol flow carrying the $\mathrm{NaNO}_{3}$ particles was reduced to below $20 \%$ through the diffusion drying tube. The asphericity of the crystallized $\mathrm{NaNO}_{3}$ particles is supported by their FWHM values of the $D_{\text {va }}$ distributions, which are consistent with that of aspherical $\left(\mathrm{NH}_{4}\right)_{2} \mathrm{SO}_{4}$ (Figs. S1 and S2).

\subsection{Application of the AAC-SPAMS system for measuring the chemically resolved $D_{\mathrm{ve}}$ and $\rho_{\mathrm{e}}$}

SPAMS can obtain information on the chemical composition of individual particles, implying that the AAC-SPAMS system has the ability to simultaneously characterize $D_{\mathrm{ve}}, \rho_{\mathrm{e}}$, and the chemical compositions of particles in real time. It is worth noting that the freshly emitted soot particles exhibit the largest $\chi(\sim 2.5)$ in the actual atmosphere (Peng et al., 2016). 
Table 1. The measured mean $D_{\mathrm{ve}}$ and its standard deviation for the eight particle types at $D_{\mathrm{a}}$ values of 250.0, 350.0, 450.0, and 550.0 nm from nine rounds of measurements.

\begin{tabular}{lrrrr}
\hline$D_{\mathrm{a}}(\mathrm{nm})$ & K-rich & EC-S & $\mathrm{K}-\mathrm{Na}$ & Amine \\
\hline 250.0 & $193.1 \pm 8.2$ & $192.2 \pm 8.1$ & $193.8 \pm 21.9$ & $190.6 \pm 4.6$ \\
350.0 & $284.0 \pm 28.4$ & $280.8 \pm 9.3$ & $271.9 \pm 18.0$ & $284.8 \pm 18.2$ \\
450.0 & $364.7 \pm 21.1$ & $357.8 \pm 6.9$ & $342.5 \pm 7.3$ & $367.9 \pm 9.7$ \\
550.0 & $416.6 \pm 28.3$ & $439.5 \pm 5.4$ & $397.3 \pm 29.7$ & $442.5 \pm 7.4$ \\
\hline$D_{\mathrm{a}}(\mathrm{nm})$ & EC-N-S & OC-N-S & OC-EC-N-S & Metal-rich \\
\hline 250.0 & $188.5 \pm 5.9$ & $200.8 \pm 17.9$ & $195.4 \pm 8.9$ & $189.0 \pm 6.7$ \\
350.0 & $281.3 \pm 9.3$ & $295.7 \pm 29.8$ & $294.0 \pm 32.3$ & $277.0 \pm 9.1$ \\
450.0 & $358.0 \pm 5.8$ & $398.3 \pm 44.3$ & $428.9 \pm 24.0$ & $342.9 \pm 10.0$ \\
550.0 & $453.2 \pm 16.4$ & $547.4 \pm 14.7$ & 570.9 & $407.4 \pm 14.5$ \\
\hline
\end{tabular}

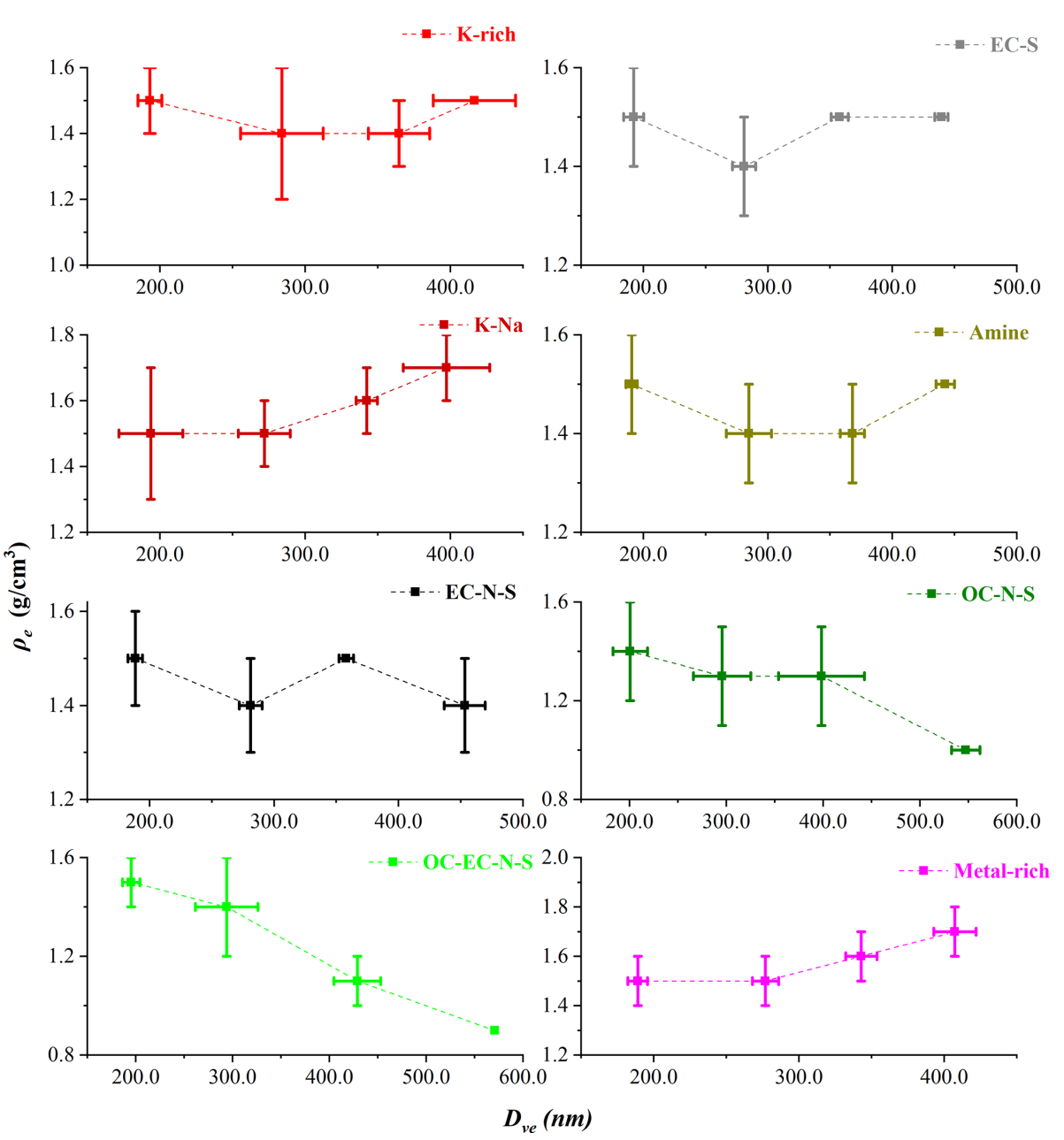

Figure 4. Variation in $\rho_{\mathrm{e}}$ of the eight particle types with $D_{\mathrm{ve}}$. The solid lines represent the range of the $\rho_{\mathrm{e}}$ and $D_{\mathrm{ve}}$ measured from nine rounds, and the data points stand for the average values. 
It meets the upper limit for the approximation between the $\chi_{\mathrm{t}}$ and $\chi_{\mathrm{v}}$ (DeCarlo et al., 2004).

As an example, the AAC-SPAMS system was deployed in the field to obtain the chemically resolved $D_{\mathrm{ve}}$ and $\rho_{\mathrm{e}}$ values for unknown aerosol particles. The sampled $\sim 100000$ particles are classified into eight major particle types with distinct chemical compositions: K-rich, EC-S, K-Na, amine, EC-N$\mathrm{S}$, OC-N-S and OC-EC-N-S, and Metal-rich, representing $97 \%$ of the detected particle population. Details of the chemical composition and number fraction of the eight types of particles are presented in the Figs. S3 and S4, respectively, which are discussed in the Supplement.

We used Gaussian fitting to obtain the $D_{\text {va }}$ peaks for each particle type with $D_{\text {a }}$ values of $250.0,350.0,450.0$, and $550.0 \mathrm{~nm}$. Following this, we calculated the $D_{\mathrm{ve}}$ values of the atmospheric particles with Eq. (11). Table 1 presents the average $D_{\text {ve }}$ values of the eight particle types, for which the standard deviation is calculated based on nine samples. The average $D_{\text {ve }}$ at $D_{\text {a }}$ values of $250.0,350.0,450.0$, and $550.0 \mathrm{~nm}$ shows wide ranges: from 188.5 to $200.8,271.9$ to $295.7,342.5$ to 428.9 , and 397.3 to $570.9 \mathrm{~nm}$, respectively, which are caused by the different chemical composition. The result indicates that particles with significantly different $D_{\mathrm{ve}}$ might possess the same $D_{\mathrm{a}}$. Furthermore, the large standard deviation of $D_{\mathrm{ve}}$, such as $21.9 \mathrm{~nm}$ for $\mathrm{K}-\mathrm{Na}$ at $250.0 \mathrm{~nm}$, $32.3 \mathrm{~nm}$ for OC-EC-N-S at $350.0 \mathrm{~nm}$, and $44.3 \mathrm{~nm}$ for OC-N$\mathrm{S}$ at $450.0 \mathrm{~nm}$, indicates that the $D_{\mathrm{ve}}$ of particles is remarkably different even for particles with the same type and same $D_{\text {a. }}$.

According to $D_{\text {ve }}$ and $D_{\text {va }}$, we calculated the $\rho_{\mathrm{e}}$ of each particle type by Eq. (12). Figure 4 shows the variations of the $\rho_{\mathrm{e}}$ with $D_{\mathrm{ve}}$ for nine particle samples. For pure compounds, such as $\left(\mathrm{NH}_{4}\right)_{2} \mathrm{SO}_{4}$ and $\mathrm{NaNO}_{3}$ particle, $\rho_{e}$ theoretically does not change with particle size. However, the sampled particles have experienced complex atmospheric processes. Therefore, $\rho_{\mathrm{e}}$ has a very wide distribution for each type of particles with a similar $D_{\mathrm{ve}}$. Specifically, the $\rho_{\mathrm{e}}$ of K-Na increases with $D_{\text {ve }}$, while the $\rho_{\mathrm{e}}$ of OC-N-S and OCEC-N-S decreases with $D_{\mathrm{ve}}$, which may be influenced by the particle shape or the material density. Additionally, the average $\rho_{\mathrm{e}}$ of each type of particle is in the order from small to large: $1.2 \pm 0.2 \mathrm{~g} / \mathrm{cm}^{3}$ for OC-EC-N-S, $1.3 \pm 0.2 \mathrm{~g} / \mathrm{cm}^{3}$ for OC-N-S, $1.4 \pm 0.1 \mathrm{~g} / \mathrm{cm}^{3}$ for K-rich, $1.4 \pm 0.1 \mathrm{~g} / \mathrm{cm}^{3}$ for amine, $1.5 \pm 0.1 \mathrm{~g} / \mathrm{cm}^{3}$ for EC-N-S, $1.5 \pm 0.1 \mathrm{~g} / \mathrm{cm}^{3}$ for EC$\mathrm{S}, 1.6 \pm 0.1 \mathrm{~g} / \mathrm{cm}^{3}$ for $\mathrm{K}-\mathrm{Na}$, and $1.6 \pm 0.1 \mathrm{~g} / \mathrm{cm}^{3}$ for Metalrich. It is reasonable to find that the average $\rho_{\mathrm{e}}$ of internally mixed particles distributes in the range of their material densities $\left(\rho_{\mathrm{m}}\right)$. For instance, the OC-EC-N-S, OC-N-S, K-rich, and amine particles, mainly comprised of internally mixed sulfate and organics, have the average $\rho_{\mathrm{e}}$ between that of sulfate with $\rho_{\mathrm{m}}$ of $1.77 \mathrm{~g} / \mathrm{cm}^{3}$ and organic aerosols with $\rho_{\mathrm{m}}$ of $1.2 \mathrm{~g} / \mathrm{cm}^{3}$ (Cross et al., 2007).

\section{Conclusion}

We develop an AAC-SPAMS system to first achieve the measurement of the $D_{\mathrm{ve}}$ and $\rho_{\mathrm{e}}$ (defined as the ratio of $\rho_{\mathrm{p}}$ to $\chi$ ) of the aspherical particles through characterizing their $D_{\mathrm{a}}$ and $D_{\mathrm{va}}$. The reliability of the AAC-SPAMS system is verified by accurately measuring the $D_{\mathrm{ve}}$ and $\rho_{\mathrm{e}}$ of PSL. Applying the AAC-SPAMS system to determine the $D_{\mathrm{ve}}$ and $\rho_{\mathrm{e}}$ of $\left(\mathrm{NH}_{4}\right)_{2} \mathrm{SO}_{4}$ and $\mathrm{NaNO}_{3}$ particles shows that these particles are aspherical and their $\rho_{\mathrm{e}}$ are independent of particle size. Coupled with the ability of SPAMS to characterize the chemical composition of individual particles, the AAC-SPAMS system is demonstrated to be capable of characterizing the $D_{\text {ve }}, \rho_{\mathrm{e}}\left(\rho_{\mathrm{p}} / \chi\right)$ and chemical compositions of atmospheric particles simultaneously, showing the potential application of this system in field observations. The approach achieves the measurement of chemically resolved $D_{\mathrm{ve}}$ and $\rho_{\mathrm{e}}\left(\rho_{\mathrm{p}} / \chi\right)$ and provides the possibility to determine their quantitative relationship with other particle properties, which would be a benefit for further reduction of the uncertainty associated with the effects of particles on air quality, human health, and radiative forcing.

Data availability. Data in this study are available at https://doi.org/10.5281/zenodo.4655206 (Peng, 2021).

Supplement. The supplement related to this article is available online at: https://doi.org/10.5194/acp-21-5605-2021-supplement.

Author contributions. The idea for the study was conceived by LP and GHZ. All experiments were performed by LP with the assistance of LL. LP wrote the paper, which was reviewed by GHZ and XHB. All co-authors discussed the results and commented on the manuscript.

Competing interests. The authors declare that they have no conflict of interest.

Acknowledgements. The authors gratefully acknowledge Cambustion Ltd., UK, for providing the AAC and Hexin Analytical Instrument Co., Ltd., China, for providing the SPAMS. This is contribution no. IS-2995 from CASGIG.

Financial support. This research has been supported by the National Nature Science Foundation of China (grant nos. 41877307 and 41775124), the Natural Science Foundation of Guangdong Province (grant no. 2019B151502022), and the Guangdong Foundation for the Program of Science and Technology Research (grant nos. 2019B121205006 and 2020B1212060053). 
Review statement. This paper was edited by James Allan and reviewed by Johannes Schneider and one anonymous referee.

\section{References}

Alexander, J. M., Bell, D. M., Imre, D., Kleiber, P. D., Grassian, V. H., and Zelenyuk, A.: Measurement of size-dependent dynamic shape factors of quartz particles in two flow regimes, Aerosol Sci. Tech., 50, 870-879, https://doi.org/10.1080/02786826.2016.1200006, 2016.

Beranek, J., Imre, D., and Zelenyuk, A.: Real-time shapebased particle separation and detailed in situ particle shape characterization, Anal. Chem., 84, 1459-1465, https://doi.org/10.1021/ac202235z, 2012.

Buseck, P. R. and Posfai, M.: Airborne minerals and related aerosol particles: effects on climate and the environment, P. Natl. Acad. Sci. USA, 96, 3372-3379, https://doi.org/10.1073/pnas.96.7.3372, 1999.

Cross, E. S., Slowik, J. G., Davidovits, P., Allan, J. D., Worsnop, D. R., Jayne, J. T., Lewis, D. K., Canagaratna, M., and Onasch, T. B.: Laboratory and ambient particle density determinations using light scattering in conjunction with aerosol mass spectrometry, Aerosol Sci. Tech., 41, 343-359, https://doi.org/10.1080/02786820701199736, 2007.

DeCarlo, P. F., Slowik, J. G., Worsnop, D. R., Davidovits, P., and Jimenez, J. L.: Particle morphology and density characterization by combined mobility and aerodynamic diameter measurements. Part 1: Theory, Aerosol Sci. Tech., 38, 1185-1205, https://doi.org/10.1080/027868290903907, 2004.

Dinar, E., Mentel, T. F., and Rudich, Y.: The density of humic acids and humic like substances (HULIS) from fresh and aged wood burning and pollution aerosol particles, Atmos. Chem. Phys., 6, 5213-5224, https://doi.org/10.5194/acp-6-5213-2006, 2006.

Guo, S., Hu, M., Zamora, M. L., Peng, J. F., Shang, D. J., Zheng, J., Du, Z. F., Wu, Z., Shao, M., Zeng, L. M., Molina, M. J., and Zhang, R. Y.: Elucidating severe urban haze formation in China, P. Natl. Acad. Sci. USA, 111, 17373-17378, 2014.

Han, C., Li, S. M., Liu, P., and Lee, P.: Size dependence of the physical characteristics of particles containing refractory black carbon in diesel vehicle exhaust, Environ. Sci. Technol., 53, 137-145, https://doi.org/10.1021/acs.est.8b04603, 2019.

Hand, J. L. and Kreidenweis, S. M.: A new method for retrieving particle refractive index and effective density from aerosol size distribution data, Aerosol Sci. Tech., 36, 1012-1026, https://doi.org/10.1080/02786820290092276, 2002.

Hoffman, R. C., Laskin, A., and Finlayson-Pitts, B. J.: Sodium nitrate particles: physical and chemical properties during hydration and dehydration, and implications for aged sea salt aerosols, J. Aerosol Sci., 35, 869-887, 2004.

Katrib, Y., Martin, S. T., Rudich, Y., Davidovits, P., Jayne, J. T., and Worsnop, D. R.: Density changes of aerosol particles as a result of chemical reaction, Atmos. Chem. Phys., 5, 275-291, https://doi.org/10.5194/acp-5-275-2005, 2005.

Kiselev, A., Wennrich, C., Stratmann, F., Wex, H., Henning, S., Mentel, T. F., Kiendler-Scharr, A., Schneider, J., Walter, S., and Lieberwirth, I.: Morphological characterization of soot aerosol particles during LACIS Experiment in
November (LExNo), J. Geophys. Res.-Atmos., 115, D11204, https://doi.org/10.1029/2009jd012635, 2010.

Li, L., Huang, Z. X., Dong, J. G., Li, M., Gao, W., Nian, H. Q., Fu, Z., Zhang, G. H., Bi, X. H., Cheng, P., and Zhou, Z.: Real time bipolar time-of-flight mass spectrometer for analyzing single aerosol particles, Int. J. Mass Spectrom., 303, 118-124, https://doi.org/10.1016/j.ijms.2011.01.017, 2011.

Liu, Y. and Daum, P. H.: Relationship of refractive index to mass density and self-consistency of mixing rules for multicomponent mixtures like ambient aerosols, J. Aerosol Sci., 39, 974-986, https://doi.org/10.1016/j.jaerosci.2008.06.006, 2008.

Liu, Z., Hu, B., Ji, D., Wang, Y., Wang, M., and Wang, Y.: Diurnal and seasonal variation of the $\mathrm{PM}_{2.5}$ apparent particle density in Beijing, China, Atmos. Environ., 120, 328-338, https://doi.org/10.1016/j.atmosenv.2015.09.005, 2015.

Moffet, R. C. and Prather, K. A.: Extending ATOFMS measurements to include refractive index and density, Anal. Chem. 77, 6535-6541, https://doi.org/10.1021/ac0503097, 2005.

Moffet, R. C., Qin, X., Rebotier, T., Furutani, H., and Prather, K. A.: Chemically segregated optical and microphysical properties of ambient aerosols measured in a single-particle mass spectrometer, J. Geophys. Res.-Atmos., 113, D12213, https://doi.org/10.1029/2007jd009393, 2008.

Peng, J. F., Hu, M., Guo, S., Du, Z. F., Zheng, J., Shang, D. J., Zamora, M., Zeng, L. M., Shao, M., Wu, Y. S., Zheng, J., Wang, Y., Glen, C., Collins, D., Molina, M., and Zhang, R. Y.: Markedly enhanced absorption and direct radiative forcing of black carbon under polluted urban environments, P. Natl. Acad. Sci. USA, 113, 4266-4271, https://doi.org/10.1073/pnas.1602310113, 2016.

Peng, L.: longer1217/All-figures-data: Data (Version V1), Zenodo, https://doi.org/10.5281/zenodo.4655206, 2021.

Peng, L. and Bi, X.: Comment on "Retrieval of atmospheric fine particulate density based on merging particle size distribution measurements: multi-instrument observation and quality control at Shouxian" by Li et al, J. Geophys. Res.-Atmos., 125, e2019JD031806, https://doi.org/10.1029/2019JD031806, 2020.

Pitz, M., Cyrys, J., Karg, E., Wiedensohler, A., Wichmann, H. E., and Heinrich, J.: Variability of apparent particle density of an urban aerosol, Environ. Sci. Technol., 37, 4336-4342, https://doi.org/10.1021/es034322p, 2003.

Pöschl, U.: Atmospheric aerosols: Composition, transformation, climate and health effects, Angew. Chem. Int. Edit., 44, 75207540, https://doi.org/10.1002/anie.200501122, 2005.

Schneider, J., Weimer, S., Drewnick, F., Borrmann, S., Helas, G., Gwaze, P., Schmid, O., Andreae, M. O., and Kirchner, U.: Mass spectrometric analysis and aerodynamic properties of various types of combustion-related aerosol particles, Int. J. Mass Spectrom., 258, 37-49, https://doi.org/10.1016/j.ijms.2006.07.008, 2006.

Seinfeld, J. and Pandis, S. N.: From air pollution to climate change, Atmospheric Chemistry and Physics, Wiley, New York, 429443, 1998.

Song, X. H., Hopke, P. K., Fergenson, D. P., and Prather, K. A.: Classification of single particles analyzed by ATOFMS using an artificial neural network, ART-2A, Anal. Chem., 71, 860-865, https://doi.org/10.1021/ac9809682, 1999.

Spencer, M. T. and Prather, K. A.: Using ATOFMS to determine OC/EC mass fractions in particles, Aerosol Sci. Tech., 40, 585594, https://doi.org/10.1080/02786820600729138, 2006. 
Spencer, M. T., Shields, L. G., and Prather, K. A.: Simultaneous measurement of the effective density and chemical composition of ambient aerosol particles, Environ. Sci. Technol., 41, 13031309, https://doi.org/10.1021/es061425+, 2007.

Sumlin, B. J., Oxford, C. R., Seo, B., Pattison, R. R., Williams, B. J., and Chakrabarty, R. K.: Density and homogeneous internal composition of primary brown carbon Aerosol, Environ. Sci. Technol., 52, 3982-3989, https://doi.org/10.1021/acs.est.8b00093, 2018.

Tang, I. N.: Thermodynamic and optical properties of mixed-salt aerosols of atmospheric importance, J. Geophys. Res.-Atmos., 102, 1883-1893, 1997.

Tang, I. N. and Munkelwitz, H. R.: Water activities, densities, and refractive-indexes of aqueous sulfates and sodium-nitrate droplets of atmospheric importance, J. Geophys. Res.-Atmos., 99, 18801-18808, 1994.

Tavakoli, F. and Olfert, J. S.: An instrument for the classification of aerosols by particle relaxation time: theoretical models of the aerodynamic aerosol classifier, Aerosol Sci. Tech., 47, 916-926, https://doi.org/10.1080/02786826.2013.802761, 2013.

Wu, Y., Xia, Y., Huang, R., Deng, Z., Tian, P., Xia, X., and Zhang, R.: A study of the morphology and effective density of externally mixed black carbon aerosols in ambient air using a size-resolved single-particle soot photometer (SP2), Atmos. Meas. Tech., 12, 4347-4359, https://doi.org/10.5194/amt-12-4347-2019, 2019.

Yin, Z., Ye, X. N., Jiang, S. Q., Tao, Y., Shi, Y., Yang, X., and Chen, J. M.: Size-resolved effective density of urban aerosols in Shanghai, Atmos. Environ., 100, 133-140, https://doi.org/10.1016/j.atmosenv.2014.10.055, 2015.

Yon, J., Bescond, A., and Ouf, F. X.: A simple semiempirical model for effective density measurements of fractal aggregates, J. Aerosol Sci., 87, 28-37, https://doi.org/10.1016/j.jaerosci.2015.05.003, 2015.
Zelenyuk, A., Cai, Y., Chieffo, L., and Imre, D.: High precision density measurements of single particles: The density of metastable phases, Aerosol Sci. Tech., 39, 972-986, https://doi.org/10.1080/02786820500380206, 2005.

Zelenyuk, A., Cai, Y., and Imre, D.: From agglomerates of spheres to irregularly shaped particles: Determination of dynamic shape factors from measurements of mobility and vacuum aerodynamic diameters, Aerosol Sci. Tech., 40, 197-217, https://doi.org/10.1080/02786820500529406, 2006.

Zhai, J., Lu, X., Li, L., Zhang, Q., Zhang, C., Chen, H., Yang, X., and Chen, J.: Size-resolved chemical composition, effective density, and optical properties of biomass burning particles, Atmos. Chem. Phys., 17, 7481-7493, https://doi.org/10.5194/acp17-7481-2017, 2017.

Zhang, G., Bi, X., Han, B., Qiu, N., Dai, S., Wang, X., Sheng, G., and $\mathrm{Fu}, \mathrm{J} .:$ Measurement of aerosol effective density by single particle mass spectrometry, Sci. China Earth Sci., 59, 320-327, https://doi.org/10.1007/s11430-015-5146-y, 2016.

Zhang, Y., Zhang, Q., Cheng, Y., Su, H., Kecorius, S., Wang, Z., Wu, Z., Hu, M., Zhu, T., Wiedensohler, A., and He, K.: Measuring the morphology and density of internally mixed black carbon with SP2 and VTDMA: new insight into the absorption enhancement of black carbon in the atmosphere, Atmos. Meas. Tech., 9, 1833-1843, https://doi.org/10.5194/amt-9-1833-2016, 2016.

Zhao, G., Zhao, W., and Zhao, C.: Method to measure the size-resolved real part of aerosol refractive index using differential mobility analyzer in tandem with singleparticle soot photometer, Atmos. Meas. Tech., 12, 3541-3550, https://doi.org/10.5194/amt-12-3541-2019, 2019. 